\title{
Racecadotril at the Beginning of Pediatric Gastroenteritis: A Small Experience of a Primary Level Hospital
}

\section{Marco Manfredi' ${ }^{1 *}$, Barbara Bizzarri ${ }^{2}$ and Gian Luigi de'Angelis ${ }^{2}$}

${ }^{1}$ Department of Medicine -Pediatric Unit, Azienda USL Reggio Emilia, Italy

${ }^{2}$ Gastroenterology and Endoscopy Unit, University of Parma, Italy

\begin{abstract}
Background: Oral rehydration (OR) as therapy in pediatric gastroenteritis, although effective, is poorly accepted by parents because of it does not reduce the frequency of bowel movements and the loss of fluids from the gut nor shortens the duration of the disease.

Racecadotril reduces secretions of intestinal fluids but it doesn't inhibit the intestinal motility.

Methods: We retrospectively reviewed 61 children affected by mild acute gastroenteritis consecutively admitted to our Pediatric Service along two years (2009 to 2010).

The children treated with Racecadotril plus OR were 26 and those treated with OR alone were 35

Results: Out of 35 children treated with Racecadotril+OR, 17 patients $(65.4 \%)$ were discharged within twentyfour hours after admission because of a marked improvement in symptoms compared with the 14/35 patients $(40.0 \%)$ of children treated with OR alone with statistically significant values $(p<0.05)$.

Children, converted to parenteral therapy due to the worsening of symptoms, were $26.9 \%$ and $42.9 \%$ in the OR+Racecadotril Group and in the OR Group respectively. We have had no side effects regarding the use of Racecadotril.

Conclusions: Our hospital is a Primary Level Hospital and we often assess children at the beginning of their symptoms. This allows us to administer Racecadotril at the onset of diarrhoea.

Our sample is small, but it shows that the early use of Racecadotril shortens the hospitalization and decreases the rate of conversion to parenteral rehydration therapy in children with mild gastroenteritis.
\end{abstract}

Keywords: Acute gastroenteritis; Children; Racecadotril; Primary care hospital

\section{Introduction}

Acute gastroenteritis in children is still one of the common cause of morbidity also in western countries and it remains a major public health problems with significant health care costs [1]. It's a usually self-limiting disease which lasts about 5-7 days; therefore the main therapeutic aim is to prevent complications such as dehydration, metabolic acidosis and electrolyte disorders. In majority of case, mild acute gastroenteritis may be treated with oral glucose electrolyte solutions (ESPGHAN guidelines) [2,3]. However, despite the proven efficacy of oral rehydration therapy (OR), this treatment is still underused, mainly because it does not reduce the frequency of bowel movements and fluid loss nor shortens the duration of the disease. This therapy is, therefore, poorly accepted, especially by parents and stimulates interest in additional treatments. Racecadotril is a pro-drug with anti-secretive effect when converted into the active metabolite. It performs its anti-diarrhoic action inhibiting intestinal encephalinasis.

The resulting increase of endogenous encephalins decreases the secretions of water and electrolyte into the lumen without interfering with the intestinal motility.

Some authors showed that children treated with Racecadotril have had a reduction of fecal output and a shortening of diarrhea duration compared with placebo, mainly in Rotavirus gastroenteritis $[4,5]$. Racecadotril, as well as reducing the fecal output and duration of diarrhea, decreases the number of clinical consultation and is well tolerated [6].
A systematic review concluded (with the limitation of small samples of the studies) that Racecadotril added to OR therapy reduces the duration of acute diarrhea in children between 3 and 48 months. Side effects did not differ from placebo [7].

\section{Patients and Methods}

Our Hospital is on the mountains (Apennines) and takes care of a very large Health District where Territorial Paediatricians are missing. Therefore, in contrast to the larger hospitals, our Service of Paediatrics must deal with situations very similar to those of the Primary Care; in fact we often visit children at the onset of their diseases.

For several years we have had a standardized protocol for the assessment of the dehydration and we have administered OR in according to the ESPGHAN parameters (Table1).

Since January 2010 we have been adding Racecadotril to OR (although not systematically) at the following doses:

*Corresponding author: Marco Manfredi, Department of Medicine-Pediatric Unit, Azienda USL Reggio Emilia, Italy, Tel: +39-522-617235; Fax: + 39-522-339643; E-mail: marco.manfredi8@gmail.com

Received December 12, 2012; Accepted February 28, 2013; Published March 04, 2013

Citation: Manfredi M, Bizzarri B, de'Angelis GL (2013) Racecadotril at the Beginning of Pediatric Gastroenteritis: A Small Experience of a Primary Level Hospital. Clin Microbial 2: 102. doi:10.4172/2327-5073.1000102

Copyright: (c) 2013 Manfredi M, et al. This is an open-access article distributed under the terms of the Creative Commons Attribution License, which permits unrestricted use, distribution, and reproduction in any medium, provided the original author and source are credited. 


\begin{tabular}{|c|c|c|}
\hline & Mild-Moderate & Severe \\
\hline Loss of weight & $5-10 \%$ & $>10 \%$ \\
General condition & Restless/lethargic & Lethargy/hypothermia \\
Tears & Reduced/absent & Absent \\
Skin elasticity & Reduced/absent & Absent \\
Mucosal hydration & Dry & Very dry \\
Refill time & Normal/prolonged(<4") & Prolonged( $>4 ")$ \\
Blood pressure & Normale/low & Low \\
Diuresis & Reduced & Oliguria \\
Heart rate & Fast & Fast/weak \\
Eyes & Sunken & Very sunken \\
Anterior fontanel & Depressed & Very depressed \\
\hline
\end{tabular}

Table 1: ESPGHAN parameters of dehydration.

children weighing less than $9 \mathrm{Kg}: 10 \mathrm{mg}$ t.i.d.

children weighing 9 to $13 \mathrm{Kg}: 20 \mathrm{mg}$ t.i.d.

children weighing 13 to $27 \mathrm{Kg}: 30 \mathrm{mg}$ t.i.d.

children weighing more than $27 \mathrm{Kg}: 60 \mathrm{mg}$ t.i.d.

Therefore, on the contrary, until December 2009 we did not use Racecadotril.

\section{Mode of administration of $O R$ in according to the ESPGHAN criteria}

\section{Phase 1}

Rehydration: small quantity of oral solutions (Gluco-electrolyte solutions) (5 ml with spoon or syringe) every 2-5 minutes (especially if there is vomiting).

The calculation of the appropriate quantity:

Slight dehydration: $50 \mathrm{ml} / \mathrm{Kg}$

Mild dehydration: $100 \mathrm{ml} / \mathrm{Kg}$

$+$

$10 \mathrm{ml} / \mathrm{Kg}$ for each liquid stool

$2 \mathrm{ml} / \mathrm{Kg}$ for each vomiting

As always recommended from ESPGHAN were used glucoelectrolyte solutions with low osmolarity.

\section{Phase 2}

Preservation: administer fluids and calories, with early recovery of nutrition (diet suitable for older also includes solid foods)

We evaluated the medical records of children $\leq 5$ years of age ( 89 children) hospitalized in our Pediatric Service for acute gastroenteritis along two years (2009 to 2010) (Figure 1).

All children were evaluated about number of bowel movements, the duration of diarrheal symptoms (at least three liquid stools a day) and the dehydration level (ESPGHAN parameters)

Twenty-eight children had a moderate-to-severe dehydration; therefore they were undergone to parenteral rehydration and were excluded from the study.

The remaining 61 children with mild dehydration (comparable as regards symptoms and ESPGHAN parameters of dehydration) underwent to the OR in according with ESPGHAN guidelines. Thirtyfive patients with gastroenteritis admitted in 2009 were treated only with OR (we have started using Racecadotril since January 2010) and 26 subsequent patients (admitted in 2010) received OR plus Racecadotril (Figure 2).

\section{Clinical patterns}

The 26 children underwent to OR+Racecadotril had an average of 4.2 liquid bowel movements daily (range between 3 and 7 stools/day); the diarrhoea lasted an average of 1.5 days (range 1 to 3 days) before the admission.

Instead, the 35 children underwent with OR alone, had an average of 4.5 liquid bowel movements daily (range between 3 and 7 stools/ day); in this case the diarrhoea lasted an average of 1.8 days with range between 1 to 5 days before the admission (Table 2 and Figure 3).

We mainly evaluated two parameters:

1. Duration of hospitalization (discharge within 24 hours after the admission) based on the disappearance or reduction of diarrheal symptoms ( $<3$ stools);

2. Switching to parenteral rehydration therapy because of persistence or worsening of the clinical symptoms.

\section{Results}

The discharged rate within 24 hours from the admission was $65.4 \%$ (17/26 children) in the Group treated with Racecadotril+OR and $40.0 \%$ (14/35 children) in the Group treated with OR alone with statistically significant value ( $\mathrm{p}=0.0499)$. These children had an evident reduction or normalization of stools consistency.

On the other hand, $7 / 26$ patients (26.9\%) in the Group treated with Racecadotril were converted to parenteral rehydration for persistence or worsening of symptoms compared to $15 / 35$ children (42.9\%) in the

Total Gastroenteritis 2009- $2010=89$ patients
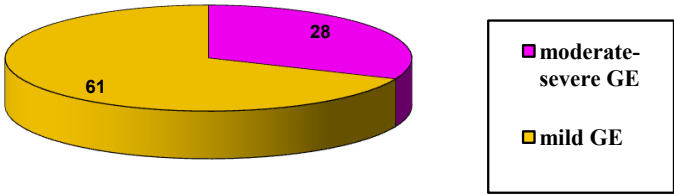

Figure 1: Total gastroenteritis (GE) admitted.

\begin{tabular}{|c|c|c|}
\hline OR + Racecadotril & OR only \\
\hline $\begin{array}{c}4.2 \text { times daily } \\
\text { (range 3-7 times daily) }\end{array}$ & $\mathrm{n}^{\circ}$ liquid bowel movements & $\begin{array}{c}4.5 \text { times daily } \\
\text { (range 3-7 times daily) }\end{array}$ \\
\hline $\begin{array}{c}1.5 \text { days } \\
\text { (range } 1-5 \text { days) }\end{array}$ & $\begin{array}{c}\text { Duration of diarrhoea before } \\
\text { admission }\end{array}$ & $\begin{array}{c}1.8 \text { days } \\
\text { (range } 1-5 \text { days) }\end{array}$ \\
\hline $\begin{array}{c}3.8 \mathrm{yr} \\
\text { (range } 6 \mathrm{~m}-4.7 \mathrm{yr} \text { ) }\end{array}$ & Age & $\begin{array}{c}4.4 \mathrm{yr} \\
\text { (range } 11 \mathrm{~m}-5 \mathrm{yr} \text { ) }\end{array}$ \\
\hline
\end{tabular}

Table 2: Characteristics of the patients at the admission.

Total patients with mild GE

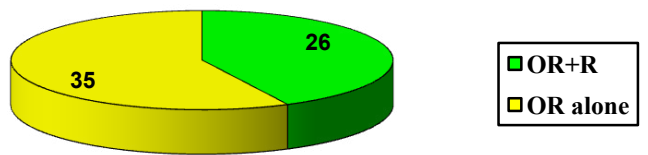

Legend: $\mathrm{OR}=$ oral rehydration; $\mathrm{R}=\mathrm{Racecadotril}$

Figure 2: Patients with mild GE (61 patients). 


\section{$\mathbf{n}^{\circ}$ liquid bowel movements/die}

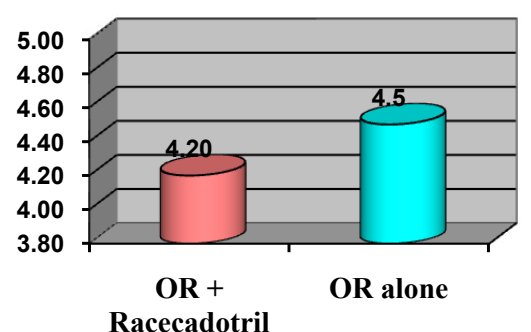

Racecadotril

duration of diarrhea in days

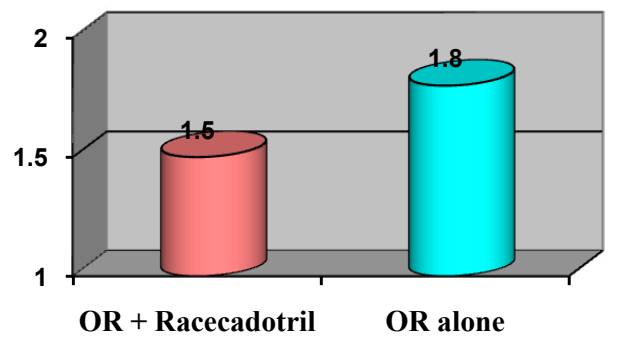

mean age (years)

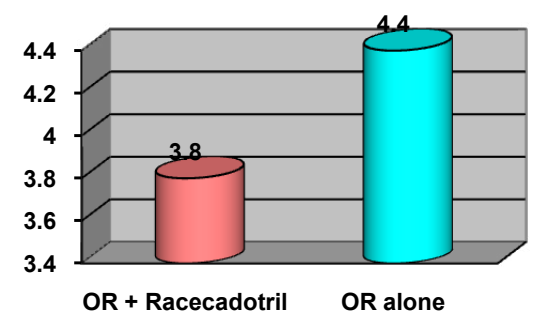

Figure 3 : Characteristics of the patients at the admission.

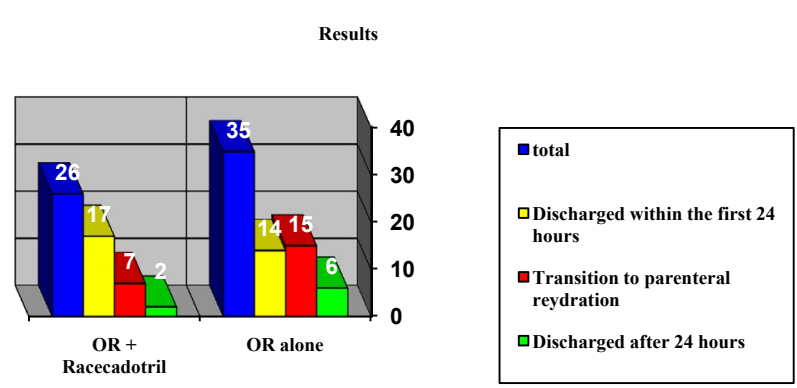

Figure 4: Results between groups.

Group treated with OR alone, with no statistically significant value $(\mathrm{p}=0.2000)$ (Figure 4).

Two patients in Group treated with Racecadotril (7.7\%) and six patients in the Group treated with OR alone (17.1\%) were discharged within 48 hours from admission, with no statistically significant value $(\mathrm{p}=0.1094)$.

We had no side effects about administration of Racecadotril, in Hospital.
However, we advised the parents to continue Racecadotril at home for an overall time of 5 days and no child is returned to our observation after Hospital discharge for a relapse of diarrhea or for side effects.

\section{Discussion}

Gastroenteritis is one of the most common diseases in children [1]. The therapy mainly recommended by the most important guidelines is the oral rehydration with glucose-electrolyte solutions, but this approach, although effective, is poorly accepted by parents because it doesn't decrease the duration of disease [2,3]. Racecadotril is an antidiarrheal drug potentially useful in gastroenteritis [4].

Our Pediatric Unit is in Primary Level Hospital and as in several areas of our mountains the Territorial pediatricians are missing, we often assess children at the onset of their diseases. Therefore, in acute gastroenteritis, we often can give the Racecadotril at the beginning of diarrhea. In our Pediatric Service, patients usually received Racecadotril at the onset of diarrheal symptoms (such as shown in this study: patients received Racecadotril after 1.7 days from the onset of diarrhea).

In this study, the early administration of Racecadotril has visually reduced the bowel movements with quick improvement of the clinical parameters and hydration of children resulting in early discharge.

By evaluating this retrospective data (considering the possible bias due to the small sample), the early treatment (during the first days of diarrhea) with Racecadotril in mild to moderate gastroenteritis in children, decreased the hospital stay and shortened the duration of diarrhea with statistically significant values $(\mathrm{p}<0.05)$. This resulted in a lesser discomfort for the child and his family and lower health costs.

Racecadotril was well tolerated and did not result in side effects such as showed by other authors [6].

In the study by Santos et al. Racecadotri did not diminish the symptoms compared with OR alone but it isn't clear how many days lasted diarrhea before the patients enrollment [8].

For the conformation of our territory, we often deal with children in early stages of their diseases, such as if we were their territorial pediatricians and perhaps for this reason we obtained good results. In fact, we administered Racecadotril in the first hours of diarrheal symptoms.

We cannot confirm these data, but our experience is to see that Racecadotril is less effective if the diarrhea has already started from few days.

For further data in support of our clinical experience, we are starting a prospective study involving the (few) Territorial Paediatricians about the early use of Racecadotril in mild-moderate acute gastroenteritis.

\section{References}

1. [No authors listed] (1996) Practice parameter: the management of acute gastroenteritis in young children. American Academy of Pediatrics, Provisional Committee on Quality Improvement, Subcommittee on Acute Gastroenteritis. Pediatrics 97: 424-435.

2. Guarino A, Albano F, Ashkenazi S, Gendrel D, Hoekstra JH, et al. (2008) European Society for Paediatric Gastroenterology, Hepatology, and Nutrition/ European Society for Paediatric Infectious Diseases evidence-based guidelines for the management of acute gastroenteritis in children in Europe. J Pediatr Gastroenterol Nutr 46: S81-S122.

3. Guarino A, Dupont C, Gorelov AV, Gottrand F, Lee JK, et al. (2012) The management of acute diarrhea in children in developed and developing areas: from evidence base to clinical practice. Expert Opin Pharmacother 13: 17-26. 
Citation: Manfredi M, Bizzarri B, de'Angelis GL (2013) Racecadotril at the Beginning of Pediatric Gastroenteritis: A Small Experience of a Primary Level Hospital. Clin Microbial 2: 102. doi:10.4172/2327-5073.1000102

Page 4 of 4

4. Salazar-Lindo E, Santisteban-Ponce J, Chea-Woo E, Gutierrez M (2000) Racecadotril in the treatment of acute watery diarrhea in children. $\mathrm{N}$ Engl J Med 343: 463-467.

5. Cézard JP, Duhamel JF, Meyer M, Pharaon I, Bellaiche M, et al. (2001) Efficacy and tolerability of racecadotril in acute diarrhea in children. Gastroenterology 120: 799-805.

6. Cojocaru B, Bocquet N, Timsit S, Wille C, Boursiquot C, et al. (2002) Effect of racecadotril in the management of acute diarrhea in infants and children. Arch Pediatr 9: 774-779.

7. Szajewska H, RuszczyÅ,ski M, Chmielewska A, Wieczorek J (2007) Systematic review: racecadotril in the treatment of acute diarrhoea in children. Aliment Pharmacol Ther 26: 807-813.

8. Santos M, Marañón R, Miguez C, Vázquez P, Sánchez C (2009) Use of racecadotril as outpatient treatment for acute gastroenteritis: a prospective, randomized, parallel study. J Pediatr 155: 62-67. 